\title{
Oligobisvelcraplex: Self-assembled Linear Oligomer by Solvophobic $\pi$ - $\pi$ Stacking Interaction of Bisvelcrands Based on Resorcin[4]arene
}

Hyejae Ihm, Jae-Suk Ahn, Myoung Soo Lah, Yongho Ko, and Kyungsoo Paek* Dedicated to Professor Dong Han Kim on the occasion of his $70^{\text {th }}$ birthday

\section{Experimental Section}

2: A mixture of the octol 1 (10 g, $10.9 \mathrm{mmol}), 2,3$-dichloroquinoxaline (8.75 $\mathrm{g}$, $43.9 \mathrm{mmol}), \mathrm{K}_{2} \mathrm{CO}_{3}(15.2 \mathrm{~g}, 0.11 \mathrm{~mol})$, and $\mathrm{DMF}(150 \mathrm{~mL})$ was stirred at room temperature for $3 \mathrm{~d}$. The mixture was filtered through celite. The filtrate solution was concentrated under vacuum and the residue was partitioned between DCM and $2 \mathrm{~N}$ HCl. The organic phase was washed with water and brine, and then dried over $\mathrm{MgSO}_{4}$. After evaporation of the solvent, the residue was chromatographed on silica gel column using an eluent of DCM, hexane, and EtoAc $(2: 6.5: 1.5)$ to give a product $(6.0 \mathrm{~g}, 40 \%)$, which was recrystallized from a mixture of DCM and isopropyl ether. M.p. $400{ }^{\circ} \mathrm{C}$ (decomp.); ${ }^{1} \mathrm{H}$ NMR $\left(400 \mathrm{MHz} \mathrm{CDCl}_{3}\right.$, $\left.3.0 \mathrm{mM}, 25{ }^{\circ} \mathrm{C}\right): \delta=0.65(\mathrm{~m}, 6 \mathrm{H}), 0.77(\mathrm{t}, 3 \mathrm{H}), 0.9-1.26(\mathrm{~m}, 24 \mathrm{H}), 1.52-1.96(\mathrm{~m}$, $8 \mathrm{H}), 2.30(\mathrm{~m}, 6 \mathrm{H}), 3.17(\mathrm{t}, 6 \mathrm{H}), 3.47(\mathrm{~s}, 2 \mathrm{H}), 3.57(\mathrm{~s}, 1 \mathrm{H}), 5.14(\mathrm{~s}, 1 \mathrm{H}), 6.05$ $(\mathrm{s}, 1 \mathrm{H}), 6.27(\mathrm{~s}, 1 \mathrm{H}), 6.64(\mathrm{~s}, 1 \mathrm{H}), 6.81(\mathrm{~s}, 1 \mathrm{H}), 6.93(\mathrm{~d}, \mathrm{~J}=8.4 \mathrm{~Hz}, 2 \mathrm{H}), 7.15$ $(\mathrm{m}, 4 \mathrm{H}), 7.30(\mathrm{~d}, \mathrm{~J}=8.4 \mathrm{~Hz}, 2 \mathrm{H}), 7.45$ (br d, 4H), 7.68 (br t, 4H), 7.80 (br t, 4H) $\mathrm{ppm} ; \mathrm{MS} \quad(\mathrm{MALDI}-\mathrm{TOF}): \mathrm{m} / \mathrm{z} \quad\left(\frac{\circ}{0}\right): 1416.27 \quad(100) \quad\left[\mathrm{M}^{+}+\mathrm{H}\right], \quad 2828.45 \quad(5) \quad\left[2 \mathrm{M}^{+}\right]$; elemental analysis calcd (을 for $\mathrm{C}_{85} \mathrm{H}_{73} \mathrm{~N}_{8} \mathrm{O}_{8} \mathrm{Br} \cdot 3 / 4 \mathrm{CH}_{2} \mathrm{Cl}_{2}$ : C $69.68, \mathrm{H} 5.44, \mathrm{~N} 7.58$; found: C 69.83, H 5.16, N 7.57 .

3: To a mixture of velcrand 2 (3.00 g, $2.1 \mathrm{mmol}), 4,4$ '-bisphenyldiboronic acid (250 mg, $1.1 \mathrm{mmol}), 2 \mathrm{M} \mathrm{KF} \mathrm{(20} \mathrm{mL),} \mathrm{degassed,} \mathrm{dry} \mathrm{THF} \mathrm{(120} \mathrm{mL),} \mathrm{and} \mathrm{ethanol} \mathrm{(10}$ mL) was added a catalytic amount of tetrakis(triphenylphosphine) palladium(0) 
under Ar atmosphere. The reaction mixture was refluxed for 1 d. After cooling to room temperature, the reaction mixture was filtered through celite. The filtrate solution was evaporated in vacuo, and the residue was partitioned between DCM and $3 \mathrm{~N} \mathrm{HCl}$. The organic phase was separated, washed with water and brine, and then dried over $\mathrm{MgSO}_{4}$. After concentration in vacuo, the crude product was purified by column chromatography using an eluent of $2 \% \mathrm{MeOH}$ in DCM to give a product (1.5 g, 45\%), which was recrystallized from a mixture of DCM and hexane. M.p. $400{ }^{\circ} \mathrm{C}$ (decomp.) ; ${ }^{1} \mathrm{H} \mathrm{NMR}\left(400 \mathrm{MHz}, \mathrm{CDCl}_{3}, 3.0 \mathrm{mM}, 25{ }^{\circ} \mathrm{C}\right): \delta=0.43$ (br $\left.\mathrm{s}, 12 \mathrm{H}\right)$, 0.75 (br s, 6H), 0.81-1.26 (m, 48H), 1.54-1.79 (m, 16H), $2.33(\mathrm{br} t, 12 \mathrm{H}), 3.17$ $(\mathrm{br} t, 12 \mathrm{H}), 3.47$ (br s, 4H), 3.57 (br s, 2H), $5.14(\mathrm{~s}, 2 \mathrm{H}), 6.03(\mathrm{~s}, 2 \mathrm{H}), 6.35$ $(\mathrm{s}, 2 \mathrm{H}), 6.78(\mathrm{~s}, 4 \mathrm{H}), 7.14(\mathrm{br} \mathrm{s}, 12 \mathrm{H}), 7.43$ (br s, 12H), 7.63 (br s, 12H), 7.78 (br s, 8H) ppm; MS (MALDI-TOF): $\mathrm{m} / z$ (\%): 2822.6 (100) [M+H]; elemental analysis calcd (응 for $\mathrm{C}_{182} \mathrm{H}_{154} \mathrm{~N}_{16} \mathrm{O}_{16} \cdot \mathrm{CH}_{2} \mathrm{Cl}_{2}$ : C 75.63, H 5.41, N 7.71; found: C 75.53, $\mathrm{H} 5.40, \mathrm{~N} 7.64$.

\section{Pulsed field gradient spin-echo (PGSE) NMR experiments. The diffusion} coefficient measurements were carried out using a 5mm Bruker QNP probe with an actively shielded $z$ gradient coil. Diffusion coefficients were extracted from a series of ${ }^{1} \mathrm{H}$ NMR spectra measured by the bipolar pulse longitudinal encodedecode (BPPLED) pulse sequence as a function of gradient amplitude. In each experiment, the gradient duration time was 2.0 or $2.5 \mathrm{~ms}$ and the amplitudes of gradient pulses ranged from 1 to $40 \mathrm{G} / \mathrm{cm}$. The diffusion time was 50 to $100 \mathrm{~ms}$. Diffusion coefficients were calculated from the data obtained by 2D diffusionordered spectroscopy (DOSY). The volume ratio, $V_{A} / V_{B}$, was calculated from the diffusion coefficient ratio $\left(V_{A} / V_{B}=\left(D_{B} / D_{A}\right)^{3}\right)$.

VPO experiment was performed with the solutions of 3 in chloroform (7-20 g/kg) using a K-7000 vapor pressure osmometer.

Polarized optical microscopy was performed on a NIKON OPTIPOT-POL polarizing 
microscope equipped with a TOSHIBA-CCD camera (1K-M34H). Selected sample (40 mM) was prepared in dissolving in $\mathrm{CHCl}_{3}$ and fibrous sample was observed by polarized optical microscopy.

The FE-SEM pictures were taken on a JSM-6700F field emission scanning electron microscope. Samples for FE-SEM were prepared by slow drying of the solution containing the bisvelcrand 3 in $\mathrm{CHCl}_{3}$ or $\mathrm{THF}$ on the surface of silicon wafer, which was followed by gold-palladium sputtering.

[*] Prof. K. Paek, Dr. H. Ihm, J.-S. Ahn

CAMDRC and Department of Chemistry

Soongsil University, Seoul 156-743, Korea

Fax: (+82) 2-822-2362

E-mail:kpaek@ssu.ac.kr

Prof. M. S. Lah

Department of Chemistry and Applied Chemistry

Hanyang University, Ansan 426-791, Korea

Prof. K. Paek, Prof. M. S. Lah

Center for Bioactive Molecular Hybrids

Yonsei University, Seoul 120-749, Korea

Dr. Yongho Ko,

Center for Smart Supramolecules

Pohang University of Science and Technology,

Pohang 790-784, Korea

[**] This work was supported by Korea Research Foundation Grant (KRF-2001-005D00015 and KRF-2003-005-C00004). 